\title{
Short Review of Self-Esteem Components with Individual Placement and Support (IPS) Strategy in People with Severe Mental Illness
}

\author{
Francisco Rodríguez Pulido ${ }^{1,2 *}$, Nayra Caballero Estebaranz ${ }^{3}$ and Dácil Oramas Pérez ${ }^{4}$ \\ ${ }^{1}$ Department of Psychiatry, University of La Laguna, Spain \\ 2Insular Plan of Psychosocial Rehabilitation, Spain \\ ${ }^{3}$ Individualized Employment Support Team (EAIE), SINPROMI, Spain \\ ${ }^{4}$ Department of Family and Community Medicine, Canary Health Service, Spain
}

\begin{abstract}
We consulted different electronic databases from 1998 to December 2015 and conducted a specific review of selfesteem components of the studies in relation to non-vocational outcomes with an Individual Placement and Support (IPS) strategy. We reviewed a total of 363 references, 83 were selected and 14 included: 9 randomized clinical trials, 1 systematic review and 4 comparative studies. We analysed the methodological quality of each of these studies using the Jadad, the Oxman and the Estabrooks scales. The findings on effectiveness in relation to non-vocational outcomes are not consistent and the evidence is still very weak.
\end{abstract}

Keywords: Schizophrenia; Employment; Rehabilitation; Evaluation; Self-esteem; Non-vocational outcomes

\section{Introduction}

Employment is one of the strategic ingredients in the recovery of people with severe and persistent mental disorder [1]. When it is obtained it is valued by the people who own it and other interested parties alike. Since it connotes a contribution to society, it breaks the selfstigma, offers the opportunity to free people from financial dependence on others (or non-contributory pensions), opens the door to more rewarding relationships based on reciprocity and shared responsibility and the effective exercise of the adult role. Competitive employment from the health perspective, has been linked to a series of psychosocial benefits, such as improving personal income, increasing self-esteem and developing social skills, as well as improving symptoms, decreasing the number of hospital admissions and eliminates stigmatization [2-7].

The Individual Placement and Support model [8] over the years has shown to be a solid approach based on scientific evidence that enables to achieve and preserve competitive jobs from the desires and preferences of each individual, even outside the US [9]. However, the results found are not so clear through this strategy, in the impact of non-vocational variables. One of these variables is self-esteem.

Motivated by the experience accumulated in more than a decade with the IPS strategy developed in Tenerife $[10,11]$, the purpose of this review is to check and analyse the quality of the results that have been published in the scientific literature during the period 1998-2015 in relation to self-esteem and employment regarding the IPS strategy.

\section{Materials and Method}

We carried out a web search of the electronic databases, MEDLINE EMBASE, SCI, PreMedline, CRD, Cochrane Library, CINAHL, PsyclNFO from 1998 to December 2015, containing the following keywords: employment, rehabilitation, serious mental disorder, Individual Placement and Support, non-vocational results and schizophrenia. We selected the studies published in English and/or Spanish during the selected period. We developed a detailed protocol to fulfil the stated objectives, which describes the following stages of the systematic search process: 1) definition of the selection criteria (inclusion and exclusion criteria), 2) search of the relevant articles published, 3) selection of titles and abstracts that meet the criteria, 4) review of the complete articles that represent the potentially selected studies, 5) critical evaluation of the quality of the selected studies and the extraction of the interesting data, and 6) analysis and synthesis of the data.
Two reviewers conducted the entire selection process of the studies. They analysed the abstracts separately and then presented the results. In case of doubt and/or disagreement, a third reviewer was consulted to check the protocol criteria and try to reach a consensus with the other two reviewers to verify the appropriate selection of the study.

\section{Inclusion and exclusion criteria}

The included studies were randomized clinical trials, systematic reviews and comparative studies. We excluded cohort studies, observational studies, economic evaluation studies, qualitative studies, historical reviews, case studies or consensus of experts' studies.

Participants: We included studies with participants who presented the following criteria:

a) Studies that followed the intervention according to the IPS model and that complied with its principles.

b) People with severe and persistent mental disorder (National Institute of Mental Health).

c) People between the ages of 18 and 65 .

d) Studies whose participants showed active dependence on substances provided they had a SMI as a primary diagnosis.

e) Studies that measure the self-esteem variable.

We excluded studies of people with organic mental disorder, learning disorder or minor psychiatric disorders, first psychotic episodes, case studies and a specific sample of people over the age of 65 .

Once we identified the studies that met the inclusion criteria, we transferred the contents to data-extraction forms previously designed by the

*Corresponding author: Francisco Rodríguez Pulido, Professor, Departmen of Psychiatry, University of La Laguna, Spain, Tel: +34609116523; E-mail: fpulido15@yahoo.es

Received November 09, 2017; Accepted November 15, 2017; Published November 22, 2017

Citation: Pulido FR, Estebaranz NC, Pérez DO (2017) Short Review of Self-Esteem Components with Individual Placement and Support (IPS) Strategy in People with Severe Mental IIIness. Int J Neurorehabilitation 4: 297. doi: 10.4172/2376 0281.1000297

Copyright: $\odot 2017$ Pulido FR, et al. This is an open-access article distributed unde the terms of the Creative Commons Attribution License, which permits unrestricted use, distribution, and reproduction in any medium, provided the original author and source are credited. 
Citation: Pulido FR, Estebaranz NC, Pérez DO (2017) Short Review of Self-Esteem Components with Individual Placement and Support (IPS) Strategy in People with Severe Mental IIIness. Int J Neurorehabilitation 4: 297. doi: 10.4172/2376-0281.1000297

reviewers' group. The quality of the studies was assessed using the Jadad scale [12] for randomized clinical trials, the Oxman scale [13] for systematic reviews and the Estabrooks scale [14] for the comparative studies.

Subsequently, the information was classified into tables following a standardised protocol to transfer the results found in non-vocational variables.

\section{Results}

We reviewed 363 references, 83 of those were selected and 14 included: 9 randomized clinical trials, 1 systematic review and 4 comparative studies.

Regarding the quality of the RCTs (Table 1), most of the studies present IB level of evidence except Bond et al. [3] (IIA) and Schneider et al. [15] (IIB), with a total quality of 3 points [16-19], 2 points $[2,20]$ and 1 point $[3,15,21]$. Concealment and blinding are not met in any of the studies reviewed.

Generally, the samples are divided into two large groups: the IPS strategy versus traditional vocational strategies (TVR). In some of the studies, such as Bond et al.s [3], the samples are classified into 4 groups. The studies present a long follow-up period (Table 2) that vary between: 18 months [3,16,18], 24 months [2,20,21], 12 months [15,17] and 30 months [19]. The predominant scale used is the Rosenberg scale [22]. Some studies have used a structured interview [21] and the scale of empowerment of mental health services [15,18].

When analysing the self-esteem variable, we observed that in the majority of analysed RCTs there were no significant differences between

\begin{tabular}{|c|c|c|c|c|c|c|}
\hline \multicolumn{7}{|c|}{ Level of quality obtained for randomized clinical trial with Jadad scale (Total score $=5$ ) } \\
\hline Study & Total quality (/5) & Randomization (/2) & Blinding (/2) & Follow up (/1) & Concealment of the assigment & Level of evidence \\
\hline Drake et al. [16] & 3 & 2 & 0 & 1 & Unknown & IB \\
\hline Mueser et al. [2,20] & 2 & 1 & 0 & 1 & Unknown & IB \\
\hline Lehman et al. [21] & 1 & 1 & 0 & 0 & Unknown & IB \\
\hline Latimer et al. [17] & 3 & 2 & 0 & 1 & Unknown & IB \\
\hline Schneider et al. [15] & 1 & 0 & 0 & 1 & Unknown & IIB \\
\hline $\begin{array}{l}\text { Areberg and } \\
\text { Bejerholm [18] }\end{array}$ & 3 & 2 & 0 & 1 & No & IB \\
\hline Michon et al. [19] & 3 & 2 & 0 & 1 & No & IB \\
\hline Bond et al. [3] & 1 & 0 & 0 & 1 & Unknown & IIA \\
\hline
\end{tabular}

Table 1: Level of quality obtained for randomized clinical trial (Jadad scale).

\begin{tabular}{|c|c|c|c|c|}
\hline Study & Groups & Follow up & Results & Scale \\
\hline Drake et al. [16] & IPS/VR & 18 months & $\begin{array}{l}\text { IPS vs. VR Baseline } 20 \text { (0.61) vs. } 19.5 \text { (0.6) Follow up } 18.5 \text { (0.70) vs. } 18.1 \\
(0.68)\end{array}$ & $\begin{array}{l}\text { Rosemberg self-esteem } \\
\text { scale }\end{array}$ \\
\hline Bond et al. [3] & $\begin{array}{l}4 \text { groups: competitive } \\
\text { work, sheltered work, } \\
\text { minimal work and no } \\
\text { work }\end{array}$ & 18 months & $\begin{array}{l}\text { Self-esteem improved between baseline and } 18 \text { months for the competitive } \\
\text { work group (within-group ES=1.17), with relatively little net change for the } \\
\text { other three groups (within-group ESs ranging from } 0.14 \text { to } 0.47 \text { ). } \\
\text {-Competitive work group had large within-group ES reflecting improvement in } \\
\text { self-esteem (ES=1.17), overall life satisfaction (ES=0.90). } \\
\text {-Baseline (M (SD)): no work } 19.6(5.6) \text { vs. minimal work } 19.3(5.4) \text { vs. } \\
\text { sheltered work } 20.6(5.4) \text { vs. competitive work } 20.5(5.9) \text { vs. total } 19.9(5.5) \\
\text {-18 months (M (SD)): no work } 18.1 \text { (6.1) vs. minimal work } 18.8(6.4) \text { vs. } \\
\text { sheltered work } 19.4(4.7) \text { vs. competitive work } 17.3(5.3) \text { vs. total } 18.4(5.8) \text {. }\end{array}$ & $\begin{array}{l}\text { Rosenberg self-esteem } \\
\text { scale }\end{array}$ \\
\hline Mueser et al. $[2,20]$ & $\begin{array}{l}\text { Psychiatric rehabilitation } \\
\text { program (PSR) and } \\
\text { Standard services } \\
\text { (Standard) }\end{array}$ & 24 months & No reported & $\begin{array}{l}\text { Rosenberg self-esteem } \\
\text { scale }\end{array}$ \\
\hline Lehman et al. [21] & $\begin{array}{l}\text { IPS y PSR } \\
\text { (Psychosocial } \\
\text { rehabilitation services) }\end{array}$ & 24 months & No reported & Structured interview \\
\hline Latimer et al. [17] & $\begin{array}{l}\text { Supported employment } \\
\text { vs. traditional vocational } \\
\text { rehabilitation }\end{array}$ & 12 months & $\begin{array}{l}\text {-Usual services (s.d) } 48.2(37.2) \text { vs. IPS } 25.6(30.8) p<0.001 \text {. } \\
\text {-OR }(95 \% \text { IC): any employment } 1(0.99-1.02) \text { vs. Competitive employment } \\
1.02(1-1.03) \text {. } \\
\text { Statistically significant time x group interaction for self-esteem }(p<0.01) \text {; this } \\
\text { variable, initially lower in the supported employment group, rises with time } \\
\text { (means: } 25.6,31.7,47.2) \text {, whereas it shows a non-significant declining trend } \\
\text { in the usual services group }(48.2,46.2,42.3) \text {. There is, however, with in the } \\
\text { IPS group no statistically significant correlation between, on the one hand, the } \\
\text { change in self-esteem score between baseline and } 12 \text { months, or on the other } \\
\text { hand, either hours in any paid employment }\end{array}$ & Self-esteem rating scale \\
\hline Schneider et al. [15] & IPS & 12 months & $\begin{array}{l}\text { Baseline } 23.2(3.6) \text { in paid work } t=2.22, p=0.028 \text {; Follow up } 22.8(3.5) t=1.71 \text {, } \\
p=0.089\end{array}$ & $\begin{array}{l}\text { Self-efficacy factor } \\
\text { from the empowerment } \\
\text { among users of mental } \\
\text { health services scale } \\
\text { (Rogers et al. [33]) }\end{array}$ \\
\hline Michon et al. [19] & IPS/VR & 30 months & $\begin{array}{l}\text { IPS vs. VR } \\
1.8(0.51) \text { vs. } 1.9(0.47)\end{array}$ & $\begin{array}{l}\text { Rosemberg self-esteem } \\
\text { scale }\end{array}$ \\
\hline $\begin{array}{l}\text { Areberg and } \\
\text { Bejerholm [18] }\end{array}$ & IPS/TVR & 18 months & $\begin{array}{l}\text { IPS vs. TVR } \\
\text { Baseline } 79(65-93) \text { vs. } 78.5(52-95) \\
18 \text { months } 81(63-88) \text { vs. } 77(58-90)\end{array}$ & Empowerment scale \\
\hline
\end{tabular}

Table 2: Results obtained in self-esteem with randomized clinical trial studies. 
groups or they did not show significant results [15] $(\mathrm{p}=0.089)$, do not show "p value" but means and medians $[3,16,19,23]$ and others do not show results $[2,20,21,24-26]$. However, the majority of the RCTs suggest a positive relationship between IPS and self-esteem (Table 2). Only in Areberg and Bejerholm's study [18] is significant $(\mathrm{p}=0.047)$ after 18 months of follow-up with the Empowerment Scale test, that it contains components of the variable self-esteem. And Nygren et al. [27] shows that competitive employment could be associated with an improvement in self-esteem compared to those people who do not get a job (mean 2.6-2.3) mentioning significant changes $(\mathrm{p}<0.05)$ in non-vocational outcomes regarding psychiatric symptoms and overall group functioning with work practice.

It seems that getting a competitive job or at least having the chance to get it can be related to the improvement of self-esteem scores. According to Schneider et al. [15], people who obtained a job had an average increase of 4.4 points in absolute terms without significant differences throughout the follow-up. According to Bond et al. [3] the competitive IPS work group obtained a considerable increase regarding the other three groups. In a study by Michon et al. [19], having a regular job was associated with a positive impact on self-esteem.
In terms of the quality level of the systematic review [24] (Table 3 ), which includes controlled trials of vocational strategies, it presents a quality level of 9 points. The scales to measure self-esteem are not mentioned. They suggest that competitive employment could be associated with an improvement in symptom control, quality of life, self-esteem and social functioning compared to those who do not get a job, without having statistically significant differences. The results are not shown in the article (Table 4).

Regarding the quality of the reviewed comparative studies (Table 5), they present a predominantly average quality (17 to 21 points), except for one of them which is high (22 points) [23]. None of them obtains a low score since the intervention is described in the control and in the treatment group. The highest scores corresponded to the "description of the intervention" and the "statistical analysis" and the lowest scores corresponded to the category of "recruitment", "inclusion/exclusion" and "outcome measures".

They present a long follow-up period (Table 6): 12 months [26,27], 24 months [25] and 30-36 months [23]. All of them use the Rosenberg scale to measure self-esteem except for an article that uses a structured

\begin{tabular}{|c|c|c|c|c|c|c|}
\hline \multicolumn{7}{|c|}{ Level of quality for systematic review (RS). Oxman scale total score=10 } \\
\hline Study & Score & Topic & Selection & Value & Quality & Combination \\
\hline Marshall et al. [24] & 9 & 2 & 2 & 2 & 2 \\
\hline
\end{tabular}

Table 3: Level of quality obtained for systematic review (Oxman scale).

\begin{tabular}{|l|l|l|l|l|}
\hline Study & Groups & Follow up & Results \\
\hline Marshall et al. [24] & $\begin{array}{l}\text { Vocational } \\
\text { rehabilitation }\end{array}$ & $\begin{array}{l}\text { Review } \\
1995-2012\end{array}$ & $\begin{array}{l}\text { Current research has not established a significant relationship between supported employment and } \\
\text { nonvocational outcomes. Secondary analysis of data from four RCTs of IPS suggested that competitive } \\
\text { employment may be associated with greater improvement over time in symptom control, quality of life, } \\
\text { self-esteem and social functioning, compared with no employment }\end{array}$ \\
\hline
\end{tabular}

Table 4: Results obtained in self-esteem with systematic review.

\begin{tabular}{|c|c|c|c|c|c|c|c|c|c|c|c|}
\hline \multicolumn{12}{|c|}{ Nivel de calidad de los estudios comparativos (EC). Escala de Estabrooks versión reducida (Puntuación total=35) } \\
\hline \multirow{2}{*}{\multicolumn{2}{|c|}{$\begin{array}{l}\text { Score } \\
(/ 30)\end{array}$}} & & \multicolumn{3}{|c|}{ Level of quality } & \multirow{3}{*}{$\begin{array}{c}\text { Recruitment } \\
\text { (/6) } \\
4(\mathrm{M})\end{array}$} & \multirow{3}{*}{$\begin{array}{c}\text { Inclusion/ } \\
\text { exclusion } \\
\text { (/4) } \\
1(L)\end{array}$} & \multirow{3}{*}{$\begin{array}{c}\text { Description of the } \\
\text { intervention (/4) } \\
2(\mathrm{M})\end{array}$} & \multirow{3}{*}{$\begin{array}{c}\begin{array}{c}\text { Statistical } \\
\text { analysis } \\
(/ 6)\end{array} \\
5(\mathrm{H})\end{array}$} & \multirow{3}{*}{$\begin{array}{c}\begin{array}{c}\text { Outcome } \\
\text { measures } \\
(/ 10)\end{array} \\
5(\mathrm{M})\end{array}$} & \multirow{3}{*}{$\begin{array}{c}\begin{array}{c}\text { Evidence } \\
\text { Level }\end{array} \\
\text { III }\end{array}$} \\
\hline & & & A & M & B & & & & & & \\
\hline Bailey et al. [26] & Medium & 17 & 1 & 3 & 1 & & & & & & \\
\hline McHugo et al. [25] & Medium & 21 & 2 & 3 & 0 & $4(\mathrm{M})$ & $4(\mathrm{H})$ & $2(\mathrm{M})$ & $6(\mathrm{H})$ & $5(\mathrm{M})$ & III \\
\hline Becker et al. [23] & High & 22 & 3 & 2 & 0 & $4(\mathrm{M})$ & $4(\mathrm{H})$ & $4(\mathrm{H})$ & $5(\mathrm{H})$ & $5(\mathrm{M})$ & III \\
\hline Nygren et al. [27] & Medium & 18 & 1 & 3 & 1 & $3(\mathrm{M})$ & $3(\mathrm{M})$ & $4(\mathrm{H})$ & $4(\mathrm{M})$ & $4(\mathrm{~L})$ & III \\
\hline
\end{tabular}

Table 5: Level of quality obtained for comparative studies (Estabrooks scale).

\begin{tabular}{|c|c|c|c|c|}
\hline Study & Groups & Follow up & Results & Scale \\
\hline $\begin{array}{l}\text { Mchugo et al. } \\
\text { [25] }\end{array}$ & $\begin{array}{l}\text { GST (Group Skills Training) vs. } \\
\text { IPS }\end{array}$ & 24 months & $\begin{array}{l}\text { Two groups that entered the extension phase were similar to the two that began } \\
\text { the experimental phase, with the IPS group reporting greater self- esteem, fewer } \\
\text { anergia symptoms, and more activation symptoms than the GST group. None of } \\
\text { these differences was clinically meaningful. } \\
\text { Not reported }\end{array}$ & Structured interview \\
\hline $\begin{array}{l}\text { Bailey et al. } \\
\text { [26] }\end{array}$ & $\begin{array}{l}\text { Community Support Program } \\
\text { (CSP) vs. IPS day treatment to } \\
\text { supported employment }\end{array}$ & 12 months & $\begin{array}{l}\text { Not reported } \\
\text { There are not significative intragroup. Their symptoms, hospitalizations, self- } \\
\text { esteem, level of nonvocational activities, and quality of life did not change. }\end{array}$ & $\begin{array}{l}\text { Rosenberg self- } \\
\text { esteem scale }\end{array}$ \\
\hline $\begin{array}{l}\text { Becker et al. } \\
\text { [23] }\end{array}$ & $\begin{array}{l}\text { Converted to supported } \\
\text { employment and a comparison } \\
\text { program that maintained day } \\
\text { treatment with a stepped } \\
\text { approach to vocational services } \\
\text { A/B/C Program }\end{array}$ & $\begin{array}{l}30 \text { to } 36 \\
\text { months }\end{array}$ & $\begin{array}{l}\text { There are not significative intragroup. } \\
\text { Mean (S.d.) baseline/follow-up: } \\
\text { Program A }(23(+/-5.6) / 23.6(+/-3.7) \\
\text { Program B }(22.1(+/-5.5) / 21.2(+/-4.1) \\
\text { Program C }(22.9(+/-4.3) / 21.7(+/-3.9)\end{array}$ & $\begin{array}{l}\text { Rosenberg self- } \\
\text { esteem scale }\end{array}$ \\
\hline $\begin{array}{l}\text { Nygren et al. } \\
\text { [27] }\end{array}$ & Vocational rehabilitation & 12 months & $\begin{array}{l}\text { Baseline (median/interquartile range) } \\
\text { Wilconxon } p<0.05 \\
\text {-Employment } 2.6(2.5) / 2.4-3.3(2-2.9) \\
\text {-Education: } 2.3(2.5) / 2-2.9(2-3.3) \\
\text {-Work practice: } 2.3(2.4) / 2.2-2.5(2.2-2.6) \\
\text {-No occupation: } 2.3(2.5) / 2.2-2.7(2.3-2.8)\end{array}$ & $\begin{array}{l}\text { Rosenberg self- } \\
\text { esteem scale }\end{array}$ \\
\hline
\end{tabular}

Table 6: Results obtained in self-esteem with comparative studies. 
interview [25]. Two of the four comparative studies show no results $[25,26]$ but reflect that the IPS group had higher self-esteem compared to the control group. The other two articles $[23,25]$ indicate that there are no significant intragroup differences. Nygren et al. [27] however, mentions that only participants in the work practice had gained significant changes in non-vocational outcomes in terms of psychiatric symptoms and global functioning (Table 6).

\section{Discussion}

We have seen that there are more and more rigorous and quality studies about interventions with IPS methodology. Regarding the quality of the analysed RCTs, we found that only four of them obtained an average score of 3 points out of 5 [16-19] and the remaining five obtained a lower score $[2,3,15,20,21]$. In all of them, the concealment or blinding is unknown or does not appear.

When analysing the findings in these studies in relation to selfesteem, we found no significant differences between groups, although in the study by Latimer et al. [17] it increases significantly in the IPS group while in the control group it has a tendency to decline without finding significant intragroup differences. Drake et al. [16] did not find significant differences in this variable. The two groups improved after 18 months of follow-up in the self-esteem variable. The authors suggest that the type of work obtained is less important (since the two groups improved) than having participated in a vocational program of employment. On the other hand, Bond et al. [3] suggests that the competitive working group obtains an effect that reflects an improvement in self-esteem, an overall satisfaction with life, while for the subscales of symptoms they were generally lower. Likewise, Schneider et al. [15] found that obtaining a job was associated with improvements in financial satisfaction and self-esteem, but the latter did not find significant differences. However, hope and self-esteem were highly correlated in the baseline and during the follow-up. Another study that found positive associations was Areberg and Bejerholm's study [18] who, using an empowerment scale that had a subscale of selfesteem, found that IPS participants obtained significantly higher scores than the control group that were less empowered at the end of the study. In Michon et al.s study [19], self-esteem was practically unchanged over time. However, having a regular job was associated with a positive impact on mental health and specifically the self-esteem component.

Likewise, when reviewing the comparative studies, two studies do not provide results $[25,26]$ but they reflect that the IPS group had higher self-esteem compared to the control group. The other two articles $[23,27]$ indicate that there are no significant intragroup differences, but, in one of them [27], it reflects that competitive employment could be associated with an improvement in self-esteem compared to those who do not obtain a job.

Regarding the quality of the systematic review that was analysed, only one study [24] obtained a high-quality level (9 points out of 10). In reference to its results, it suggests that competitive employment could be associated with an improvement on symptom control, quality of life, self-esteem and social functioning compared to those who do not obtain a job. However, these differences are not statistically significant and sometimes health impact is not valued.

However, we find limitations of this set of studies that should be taken into account. In this short review on the variable self-esteem and its relation to the ordinary employment of people with severe mental disorder we find that one of the first limitations is the follow-up time of the studies. The follow-up times of the analysed studies are not homogeneous and range from 12 to 36 months. This could influence the analysis of the final results and their possible interpretations. Selfesteem is manifested through thoughts, feelings and attitudes of the human being. At an adequate level, the person can be better prepared to accept the challenges and turn obstacles that may arise in a certain job into stimuli. Some experts suggest that the structure provided by the habit of going to work and by the work environment can help to combat the symptoms of the disease [28]. In addition, employment provides opportunities to develop alternative social relationships outside of the mental health community $[29,30]$ that can make people feel better. However, these positive influences could be observed in the long term rather than in the short term, in the permanence of a job and even more so, if the time of evolution of the disease and the period of inactivity has been long.

On the other hand, another of the limitations regarding nonvocational results is that there is no consensus in the tests that were used to measure each one of the variables, making it difficult to draw firm conclusions in this aspect. In the studies, nine of them used the Rosenberg Self-Esteem Scale test [22] but the rest used different scales, structured interviews or simply do not specify the tests used. In addition, some studies do not specify results of the obtained scores in the tests, but, in the end, associations with the self-esteem variable appear.

Another aspect that can influence the analysed results is the motivation of the patients. Recent formulations suggest that cognition and negative symptoms are related to motivation and arise at different times of the development $[31,32]$.

Therefore, a larger number of homogeneous studies would be necessary, with larger sample sizes, with longer follow-up times and specifying in all studies the tests used and results obtained from the baseline to the end of the follow-up in all groups studied so that the information is clear and precise. This would make it easier to consistently estimate the validity of each proposed intervention method, as well as to guide the action in daily clinical practice and the creation of effective treatments directed to a specific population of treatment [33].

Although the results are promising, even in people who have not been successful in employment with the IPS model, more studies are needed to further deepen the benefits of non-vocational variables and their associations.

\section{Conclusion}

We verified that we obtained good results with the IPS strategy in the employment of people with severe mental disorder. However, the conclusions about the results related to self-esteem are not conclusive having to clarify many of their components for quality research. Also, the relationship of self-esteem and quality of life, number of hospital admissions, and the symptomatology should be studied in order to obtain firm conclusions for the future.

\section{Acknowledgement}

SINPROMI, IASS and Cabildo of Tenerife.

\section{References}

1. Rodríguez PF (2010) La recuperación de las personas con trastorno menta grave. Modelo Red de Redes. Fundación Canaria de Salud y Sanidad de Tenerife.

2. Mueser KT, Becker DR, Torrey WC, Xie H, Bond GR, et al. (1997) Work and nonvocational domains of functioning in persons with severe mental illness: $A$ longitudinal analysis. J Nerv Ment Dis 185: 419-426. 
Citation: Pulido FR, Estebaranz NC, Pérez DO (2017) Short Review of Self-Esteem Components with Individual Placement and Support (IPS) Strategy in People with Severe Mental IIIness. Int J Neurorehabilitation 4: 297. doi: 10.4172/2376-0281.1000297

3. Bond GR, Resnick SG, Drake RE, Xie H, McHugo GJ, et al. (2001) Does competitive employment improve nonvocational outcomes for people with severe mental illness? J Consult Clin Psychol 69: 489-501.

4. Burns T, Catty J, White S, Becker T, Koletsi M, et al. (2009) The impact of supported employment and working on clinical and social functioning: Results of an international study of individual placement and support. Schizophr Bull 35: $949-958$

5. Corbière $M$, Lecomte $T$ (2009) Vocational services offered to people with severe mental illness. J Ment Health 18: 38-50.

6. Perkins D, Raines J, Tschopp M, Warner T (2009) Gainful employment reduces stigma toward people recovering from schizophrenia. Community Ment Health J 45: 158-162.

7. Gold PB, Macias C, Rodican CF (2016) Does competitive work improve quality of life for adults with severe mental illness? Evidence from a randomized trial of supported employment. J Behav Health Serv Res 43: 155.

8. Bond GR (1998) Principles of the individual placement and support model: Empirical support. Psychiatr Rehabil J 22: 11-23.

9. Bond GR, Drake RE, Becker DR (2012) Generalizability of the individual placement and support (IPS) model of supported employment outside the US. World Psychiatry 11: 32-39.

10. Rodriguez PF (2011) La autonomía personal en el empleo ordinario de las personas con trastorno mental grave. Sinpromi, Tenerife.

11. Rodríguez PF, Caballero EN, Tallo AE, Méndez AM, Álvarez-Sotomayor HMC, et al. (2017) Efectividad de un programa de apoyo individualizado al empleo para personas con trastornos mentales graves, en una región con alto desempleo. Gaceta Sanitaria.

12. Jadad AR, Moore RA, Carroll D, Jenkinson C, Reynolds JM, et al. (1996) Assessing the quality of reports of randomized clinical trials: Is blinding necessary? Controlled Clin Trials 17: 112.

13. Oxman AD, Cook DJ, Guyatt GH (1994) Users' guides to the medical literature VI. How to use an overview. Evidence-based medicine working group. JAMA 272: 1367-1371.

14. Estabrooks CA, Goel VE, Pinfold SP, Sawka C, Williams J (2000) Consumer decision aids: Where do we stand? A systematic review of structured consumer decision aids. ICES Technical Report.

15. Schneider J, Slade J, Secker J, Rinaldi M, Boyce M, et al. (2009) SESAMI study of employment support for people with severe mental health problems: 12 month outcomes. Health Soc Care Community 17: 151-158.

16. Drake RE, McHugo GJ, Bebout RR, Becker DR, Harris M, et al. (1999) A randomized clinical trial of supported employment for inner-city patients with severe mental disorders. Arch Gen Psychiatry 56: 627-33.

17. Latimer EA, Lecomte T, Becker DR, Drake RE, Duclos I, et al. (2006) Generalisability of the individual placement and support model of supported employment: Results of a Canadian randomised controlled trial. Br J Psychiatry 189: $65-73$.
18. Areberg C, Bejerholm U (2013) The effect of IPS on participants' engagement quality of life, empowerment and motivation: A randomized controlled trial. Scand J Occup 20: 420-428.

19. Michon $\mathrm{H}$, van Busschbach JT, Stant AD, van Vugt MD, van Weeghel J, et al (2014) Efectiveness of individual placement and support for people with severe mental illness in Netherlands: A 30 month randomized controlled trial. Psychiatr Rehabil J 37: 129-136.

20. Mueser KT, Becker DR, Wolfe R (2001) Supported employment, job preferences, job tenure and satisfaction. J Ment Health 10: 411-417.

21. Lehman AF, Goldberg R, Dixon LB, McNary S, Postrado L, et al. (2002) Improving employment outcomes for persons with severe mental illnesses. Arch Gen Psychiatry 59: 165-172.

22. Rosenberg M (1965) Society and the adolescent self-image. Princeton University Press, Princeton, NJ.

23. Becker DR, Bond GR, McCarthy D, McCarthy D, Thompson D, et al. (2001) Converting day treatment centers to supported employment programs in Rhode Island. Psychiatr Serv 52: 351-357.

24. Marshall T, Goldberg RW, Braude L, Dougherty RH, Daniels AS, et al. (2014) Supported employment: Assessing the evidence. Psychiatr Serv 65: 16-23.

25. McHugo GJ, Drake RE, Becker DR (1998) The durability of supported employment effects. Psychiatr Rehabil J 22: 55-61.

26. Bailey EL, Ricketts SK, Becker DR, Xie H, Drake RE (1998) Do long-term day treatment clients benefit from supported employment? Psychiatr Rehabil J 22 24-29.

27. Nygren U, Markström U, Svensson B, Hansson L, Sandlund M (2011) Individual placement and support - A model to get employed for people with mental illness - The first Swedish report of outcomes. Scand J Caring Sci 25: 591-598.

28. Marrone J, Golowa E (1999) If work makes people with mental illness sick what do unemployment, poverty and social isolation cause? Psychiatr Rehabil J 23: 187-193

29. Gates LB, Akabas SH, Oran-Sabia V (1998) Relationship accommodations involving the work group: Improving work prognosis for persons with mental health conditions. Psychiatr Rehabil J 21: 264-272.

30. Rollins AL, Mueser KT, Bond GR, Becker DR (2002) Social relationships a work: Does the employment model make a difference? Psychiatr Rehabil J 26: 51-61

31. Beck AT, Rector NA, Stolar N, Grant P (2009) Schizophrenia: Cognitive theory, research and therapy. Guilford Press, New York.

32. Grant PM, Beck AT (2009) Defeatist beliefs as a mediator of cognitive impairment, negative symptoms, and functioning in schizophrenia. Schizophr Bull 35: 798-806

33. Rogers ES, Chamberlin J, Ellison ML, Crean T (1997) A consumer-constructed scale to measure empowerment among users of mental health services. Psychiatr Serv 48: 1042-1047. 